\title{
HUELLAS DEL RELATIVISMO DE PROTÁGORAS EN EL ESCEPTICISMO ANTIGUO
}

\author{
Marisa Divenosa \\ Universidad de Buenos Aires \\ Unversidad de Mar del Plata
}

Resumen: El presente artículo avanza sobre las relaciones existentes entre el pensamiento de Protágoras y del escepticismo representado por Pirrón de Elis. Analizando el concepto de antilogías y contextualizando la declaración de imposibilidad de contradecir que habría sostenido el sofista, puede verse hasta qué punto su concepción ontológica, basada en la fluctuación y la construcción constante de la realidad mundana por parte de cada hombre, conlleva la imposibilidad de llegar a contradicciones, incluso cuando dos proposiciones se niegan mutuamente.

Sobre una ontología muy cercana, Pirrón asume la imposibilidad de la predicación, como consecuencia, también, de la aprehensión de la realidad por parte del hombre. La suspensión del juicio (epoché), la indiferencia (adiaphoría), la impasividad (apátheia), la tranquilidad (ataraxía) son, dentro del ámbito de la acción, lo que corresponde a la aphasía en el ámbito del discurso. El pensamiento de este escéptico antiguo recoge de este modo la línea de concepción ontológica relativista de Protágoras, profundizando incluso alguno de sus rasgos.

Palabras clave: relativismo, antilogías, escepticismo, aphasía.

Abstract: The present article puts forward the existing relations between the thought of Protagoras and of the scepticism represented by Pyrrho from Elis. Analyzing the concept of contradictions and putting in context the declaration of impossibility to contradict that the sophist would support, it shows up to what point his ontological conception, based on the fluctuation and the constant construction of the mundane reality on the part of every man, carries the impossibility to come to contradictions, even when two propositions contradict one another.

On a very near ontology, Pyrrho assumes the impossibility of speaking, also as a consequence of the apprehension of the reality on the part of man. The suspension of judgment (epoché), the indifference (adiaphoria), the impassivity (apátheia), the tranquillity 
(ataraxia) are, in the ground of action, the correspondence of aphasia in the ground of speech. The thought of this ancient sceptic gathers thus the line of ontological relativist conception of Protagoras, deepening even someone of its features.

Keywords: relativism, antilogies, scepticism, aphasia.

La posición relativista de Protágoras está expresada, en su esencia, en el fragmento que lo hizo famoso: "El hombre es la medida de todas las cosas, de lo que es, en tanto que es, y de lo que no es, en tanto no es" (80B1). ${ }^{1}$ Sin embargo, la manera en que este relativismo debe ser entendido está lejos de ser clara y unánimemente interpretada. Las formas de pensarlo fluctúan entre posiciones que comprenden ánthropos en un sentido individual y que supone una atomización de las creencias, de la construcción de la realidad, hasta quienes lo conciben refiriendo a la universalidad humana, pasando por argumentaciones que moderan estas dos, tales como la de quienes piensan que el sofista comprende 'hombre' como 'ser social o culturalmente entendido', vale decir, con una opinión modelada por su contexto intersubjetivo. Nuestra interpretación del relativismo de Protágoras comprende que, en sus líneas generales, se trata pensar al hombre inserto en una doble dimensión: una diacrónica, que toma en cuenta la historia de cada individuo, un cúmulo de experiencias linealmente distribuidas desde su nacimiento hasta su muerte; y una dimensión sincrónica, en la que este hombre toma contacto con un complejo ámbito externo a él, a partir del cual, a cada momento, es capaz de seleccionar ciertas determinaciones que forman parte de su mundo, así humanizado. Los demás hombres, también parte de este mundo antropológicamente determinado de manera dinámica, completan su propia concepción en el mismo gesto de completar la de la realidad. Fluctuante, dinámico, cambiante, tanto el hombre como su mundo se redefinen de manera constante e instantánea.

Los abiertos rechazos de este relativismo que se presentan en la obra de Platón ${ }^{2}$ han aplazado el progreso inmediato que, en otro contexto, la innovación y originalidad de la posición hubiera tenido. Probablemente, el paradigma reinante del que el filósofo fue portavoz logró obturar el avance

1 80B1 Sexto Emp., Contr. Mat. VII 60.

2 Cf. Teeteto $176 s s$. 
de la línea relativista, pero la fuerza de la argumentación antilógica, latente pero viva, volvió a encarnarse en el pensamiento griego posplatónico.

Este trabajo intenta trazar la línea de continuidad del relativismo protagórico que no ha sido acallada por la tradición: la que se conservó en la posición escéptica antigua. Para ello, y en la perspectiva de un artículo que sea capaz de un análisis sostenido y puntual, tomaremos puntualmente el problema de la predicación y de la posibilidad de establecer un discurso verdadero que han visto tanto Protágoras como Pirrón. Articularemos nuestro desarrollo en tres secciones principales, que nos permitirán: 1. esclarecer en qué sentido deben entenderse las antilogías de Protágoras, y sus implicaciones ontológicas; en este caso, será constructivo revisar la interpretación que de las mismas aporta Platón en su Eutidemo y Aristóteles en Metafisica, ya que estos filósofos aportan las primeras reflexiones sobre las implicaciones lógicas que supone la posición relativista. 2. Presentar testimonios del pensamiento de Pirrón de Elis -principalmente a través de Timón de Fliunte referido por Aristocles en la obra de Eusebio, y en Sexto Empírico-, en lo que concierne a su concepción ontológica y las consecuencias que tal concepción tiene a nivel discursivo. 3. Concluir acerca del alcance que las antilogías, sus supuestos e implicaciones tuvieron en las primeras manifestaciones escépticas, y ver hasta qué punto la posición protagórica y la pirrónica descansan en la misma concepción de la realidad.

\section{I}

Diógenes Laercio abre el panorama de las antilogías de Protágoras, colocándolas directamente en relación con Platón:

"Euforión y Panetios dijeron que el comienzo de la República [de Platón] ha sido reelaborado a menudo. Y Aristóxeno dice que la República fue escrita casi en su totalidad en las Antilogías de Protágoras." 
"La República se encuentra casi enteramente en las Antilogías

de Protágoras, dice Favorito en el segundo libro de su Historia Variada."3

La relación de las Antilogías con la República es incierta, y hay una cantidad considerable de autores que la consideran falsa. Sin embargo, tal como A. Melero Bellido señala, ${ }^{4}$ no parece imposible que Protágoras haya estado sumamente implicado en las cuestiones tematizadas en el texto de Platón, y que esto haya ayudado a que la tradición conectó las dos obras. La preocupación política del sofista está bien atestiguada, y pudo haber tomado forma en el proyecto de una ciudad ideal, tal como la que Platón propone a partir del libro II de su República; de modo que esto puede dar la impresión de que Protágoras habría "incluido" -anacrónicamente, claro, pero aludiendo al contenido del diálogo- los desarrollos de la República en su texto. Indudablemente, más allá de esta relación imposible de verificar, es claro que Diógenes realizó un real aporte sobre el pensamiento del sofista, al informar sobre esta obra que llevaba por nombre "Discursos contradictorios".

En el párrafo 53 del mismo texto de Diógenes Laercio (DK 80A1) leemos la célebre afirmación "ouk éstin antilégein", atribuida allí a Antístenes y a Pródico. ${ }^{5}$ Rápidamente, Diógenes explica que Protágoras fue el primero en debatir esta idea públicamente, apoyando su opinión en el pasaje 286e del Eutidemo de Platon. ${ }^{6}$ Este texto, que constituye precisamente el testimonio 19 sobre el sofista, dice:

"He entendido a menudo esta tesis de boca de mucha gente y siempre me sorprende. Estaba muy de moda en la escuela de Protágoras, y aun entre los más antiguos. Yo siempre la

3 80B5 DK Dióg. Laerc. III, 37.

${ }^{4}$ A. Melero Bellido, en su comentario a la traducción de Los Sofistas. Testimonios y Fragmentos, 1996, p. 121122, n. 67.

${ }^{5}$ Confirmado la paternidad de la idea de que es imposible contradecir, ver Platón, Euthid. 285e-6c8, y Séneca, Ep. 88, 43 80A20b DK. Cf. Mi-Kyoung Lee, Epistemology After Protagoras, Apéndice. Cf. tb. George Kerferd, The Sophists and Their Legacy.

6 La explicación de A. Melero Bellido (p. 86, n. 19) sobre el origen de esta opinión según la cual Antístenes habría sostenido que toda declaración tiene un fundamento, mientras que para Protágoras todo carece de fundamenteo parece interesante, pero los testimonios no permiten verificarla. 
encontré sorprendente; me parece que arruina a las otras y se arruina a sí misma."7

Para el Sócrates del Eutidemo se trataría de una afirmación que se niega a sí misma. En realidad, si la ontología y la gnoseología de Protágoras implican la imposibilidad de que una percepción sea falsa -ya que siempre responde a un estado de conciencia de quien percibe-, la consecuencia es que ningún discurso puede mostrar falsedad. Así, en el Eutidemo:

"Dos afirmaciones contradictorias suponen en consecuencia: a) que no son verdaderamente contradictorias, b) que hacen referencia a objetos diferentes, c) que una de ellas no se refiere a nada." 8

El lenguaje acompaña un estado de cosas, y nada más. ${ }^{9}$ Volveremos sobre estas declaraciones del Eutidemo, pero veamos antes el último testimonio conservado sobre la posibilidad de antilégein, es decir, de 'decir lo contrario', 'contradecir', 'decir un discurso opuesto/contrario'. Se trata de DK 80A15 (Sexto Empírico, Adv. Math. VII, 389), donde se afirma que, si toda representación es verdadera, la representación que establece que toda representación no es verdadera debería también ser verdadera -pues ella también constituye una representación-, y es por esta vía que la declaración ouk éstin antilégein se vuelve contradictoria. El propio Diógenes Laercio amplía el testimonio y explicita en 80B6a:

"Protágoras fue el primero en decir que sobre todo tema existen dos discursos mutuamente opuestos (antikeiménous allélos)." 10

El participio antikeímenos, compuesto por la preposición antí, “contra”, “anti-”, y del verbo keímai, 'encontrarse', 'yacer', tiene en su esencia la idea de permanecer en oposición, estar en contradicción una cosa con otra. En el fondo, la afirmación de Diógenes implica que el discurso sigue la

\footnotetext{
${ }^{7} \mathrm{PI}$, Eutid. 286 b-c.

8 BELLIDO, p. 103, n. 52.

${ }^{9} \mathrm{Cf}$. la referencia a la misma idea en Arist., Met., VI 4, $1007 \mathrm{~b} 18$.

10 Inserto en 80A1 DK Dióg. Laer., IX, 51.
} 
estructura fluctuante e indefinida de la realidad, que no puede ser determinada por el pensamiento en una sola fórmula unitaria y absoluta. El lógos se revela así, también, relativo a lo situacional, ${ }^{11}$ de modo que antilégein sería extensivo, el correlato discursivo, de la realidad antikeímenon. Si estas declaraciones sobre los discursos dobles adquieren valor es en la perspectiva general del relativismo de Protágoras delineado en el fragmento 1 ya referido, y haciendo centro en las partes a y b del fragmento DK $80 \mathrm{~B} 6 .^{12}$ Es aquí donde se habla de dúo lógoi y de discursos hétton y kreítton, discursos que pueden cambiar sus determinaciones cualitativas. Veamos ahora $80 \mathrm{~B} 6 \mathrm{~b},{ }^{13}$ que suele ser traducido:

\section{"Hacer más débil el argumento más fuerte."14}

Lo hemos visto, los testimonios 80A1 (51), A19, A20, A21 van en el mismo sentido que el fragmento transmitido por Aristóteles, ya que dicen que Protágoras fue el primero en establecer que siempre hay un argumento opuesto a cualquier otro, y en consecuencia es imposible llegar a una contradicción, porque ambos tienen igual valor. Como puede verse, hay en realidad dos temas diferentes en el mismo fragmento, porque una cosa es decir que existen argumentos opuestos, y otra es afirmar la existencia de un argumento débil y de un argumento fuerte, y la posibilidad de transformar uno en el otro. Pero a priori los críticos -especialmente Diels y Kranz, en su organización del material del sofista- consideraron que se trata de ideas complementarias o de diferentes aspectos de la misma idea. En rigor, si todos los discursos tienen el mismo valor de verdad, y si no existe posibilidad de contradecir, entonces ¿cómo habría criterio que permita determinar si un discurso es mejor que otro?

El fragmento citado, $80 \mathrm{~B} 6 \mathrm{~b}$, tiene una estructura sintáctica simple; no hay verbo conjugado, porque forma parte de un discurso indirecto. Está compuesto por dos adjetivos comparativos, hétto ('inferior a', 'menor que', 'que se deja vencer', 'más débil en el combate', y también 'incapaz de resistir'

\footnotetext{
11 Cf también 80A20 DK, donde Clemente de Alejandría (Miscel. VI, 65) confirma las ideas presentes en Diógenes Laercio.

12 El fragmento 6 está compuesta en rigor por tres partes: 80B6 Cicerón Brut. 12, 46 (cf. nota siguiente); 80B6a Diógenes Laercio IX 51; 80B6b Aristóteles, Retórica II 24 1402a23.

13 80B6b DK Ar., Ret., 1402a25.

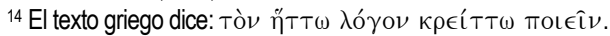


-por el cansancio, por ejemplo), ${ }^{15}$ y kreítto (en general, se lo utiliza como lo contrario de hétto, forma comparativa de krátos. ${ }^{16}$ 'más fuerte' -físicamente-, 'más poderoso', 'que está por encima', 'que sobrepasa'). ${ }^{17}$

¿Cómo debe comprenderse entonces el sentido de este fragmento, en relación con el pensamiento del sofista? La interpretación de Mario Untersteiner nos parece, sobre este punto, sumamente rica. El crítico sugiere que lo que es mejor o peor, más fuerte o más débil, son las posibilidades de una opinión humana, en el marco de una sociedad. Para él, que el hombre sea métron significa que es quien domina su conocimiento y, entonces, su forma de insertarse en el mundo. Domina, en el fondo, su experiencia. ${ }^{18}$ En consecuencia, con esta interpretación y teniendo en cuenta la apología de Protágoras hecha en el Teeteto, ${ }^{19}$ el fragmento $6 \mathrm{~b}$ se referiría a un estado mejor que otro, al que debe llegarse a través del dominio de la experiencia y del conocimiento. ${ }^{20} \mathrm{Y}$ se dice bien "mejor que otro" y no "más verdadero que otro”, pues vista la concepción de una percepción siempre verdadera, no puede decirse que haya opiniones falsas. Siendo todas verdaderas, la única alternativa para comprender la diferencia de valor de los argumentos es considerar el valor relativo que tienen en el marco de lo que es útil a un hombre, a un contexto, a una sociedad.

(...) "creo más bien que aquel que, en virtud de una disposición (héxis) inferior de su alma, tiene opiniones de la misma naturaleza que su alma es conducido, por una disposición superior, a tener opiniones conformes a esta superioridad."21

Es por esto que M. Untersteiner considera que se trata de cambiar como hacen los fármacos con las condiciones de percepción y dentro de las

\footnotetext{
15 PI., Prot. 355a4-356a1.

16 'Fuerza física', 'dominación', 'poder'. krateîn : 'ser fuerte', 'dominar' ; 'volver se una regla'.

17 Este fragmento ha generado una doble tradición interpretativa: una negativa (peyorativa) 0 «aristotélica», representada por Lane Cooper (1932, p. 177, citado por Edward Schiappa, Protagoras and Logos. A Study in Greek Philosophy and Rhetoric, 2003, p. 103): «making the worst appear the better cause». En esta misma vía, J. Freese: «making the worst appear the better argument » y W. Rhys Robert: «making the worst argument seems the better»; y otra tradición de interpretación «heraclíea» o positiva. Cf. también SCHIAPPA, 2003, p. $107 \mathrm{ss}$.

18 UNTERSTEINER, 1993, p. 30-35, 52-61.

${ }^{19} \mathrm{Pl} .$, Teet. 166a-168c.

20 UNTERSTEINER, 1993, p. 87.

21 UNTERSTEINER, 1993, p. 87. Pl., Théét., 167d: "Es así cómo, a la vez, unos son más sabios que otros, siendo que ninguno tiene opiniones falsas."
} 
posibilidades de cada hombre particular-, los diferentes grados de inteligibilidad que logran los hombres respecto de las cosas; modificar el lugar que ellas tienen en la red de valores humanos en que se insertan. De esta manera, el kreítton lógos implica que

"la cognoscibilidad superior de una cosa debe sustituir una cognoscibilidad menor de esa misma cosa, es decir el hétton lógon."22

Así, el kreítton lógos es más abstracto y universal que el hétton lógos, correspondiendo este último al estado natural del flujo constante, antes de la intervención matricia o dominadora humana, la "condición inmediata de cognoscibilidad para un individuo simple". ${ }^{23} \mathrm{La}$ interpretación de Untersteiner ve en la antropología del sofista la idea de que, cuando el hombre sustituye un conocimiento por otro, su ser individual pasa a un mayor grado de universalidad. Por otra parte, en su proyección social, la afirmación implica un cambio en lo que la ciudad considera malo o no benéfico, por otra opinión cuyo valor viene del hecho de que implica una condición general mejor que la precedente. El concepto de justicia que cada ciudad sostiene y que enseña a sus ciudadanos, está elegido porque lo considera mejor para ella. En esta elección, el sofista tendría un rol no menor, en la medida en que contribuye a esta formación y a mantener actualizados estos valores. Es entonces propio de hombres sabios o prudentes e inteligentes el ser capaces de discernir lo superior de lo inferior, y de proponer opiniones kreitton para reemplazar las opiniones hétton. Según Untersteiner, ${ }^{24}$ el discurso más fuerte representa el discurso mejor, el que prepara al pensamiento para concebir el concepto, abstracto e universal, que debe reemplazar la experiencia inmediata, particular y materia de cada hombre individual. Es decir que, en su avance en el conocimiento de la naturaleza humana y de la naturaleza del mundo, el hombre debe liberarse de los aspectos singulares de su experiencia y ganar en la universalidad de su propio concepto.

\footnotetext{
22 UNTERSTEINER, 1993, p. 88.

${ }^{23}$ Idem, p. 73-80.

24 Idem, p. 87-88.
} 
En este contexto, la imposibilidad de contradecir responde a que, en primer lugar, si todo discurso expresa perspectivas particulares de la realidad, no hay discurso falso. Y, en segundo término, cada uno de los discursos debe insertarse en aquella perspectiva en la que su aporte es mejor.

Es pertinente aquí recordar las declaraciones que, a propósito de la imposibilidad de contradecir, Aristóteles vierte en Metafísica 1011b7ss. Allí, el filósofo intenta demostrar el error que cometería Protágoras al concebir que, tanto una proposición como su contraria son verdaderas, pues esto implica para el filósofo la negación del Principio de no-Contradicción.

(...) "Además, si todas las contradicciones fueran verdaderas a la vez del mismo sujeto, es evidente que todas las cosas serán una sola. La misma cosa sería, en efecto, trirreme y muro y hombre, si es que un predicado cualquiera puede afirmarse o negarse de todo, como sucede necesariamente a los que afirman la doctrina de Protágoras. ${ }^{25}$ En efecto, si a alguien le parece que un hombre no es trirreme, evidentemente no es trirreme y, por tanto, también lo es, supuesto que la contradicción es verdadera. Y resulta de la Anaxágoras: todas las cosas confundidas [Cf. DK 59A1 (II, 32, 11)] y, por tanto, nada existe verdaderamente. Parecen, ciertamente, hablar de lo indeterminado, y aunque creen que se refieren a lo que es, hablan acerca de lo que no es: lo que es potencialmente y no plenamente actualizado es, desde luego, lo indeterminado (aóriston). Pero estos se ven forzados a admitir que de todo puede predicarse cualquier afirmación o cualquier negación."26

El filósofo habla, en el pasaje, de clases de objetos, de manera que frente a un 'médico', por ejemplo, lejos de existir una infinidad de elementos respecto de los cuales se defina, aparece la clase de los 'pacientes' como aquella respecto de la cual se determina por antonomasia. Consecuentemente, Aristóteles niega la tesis de Protágoras de que todo es relativo a un perceptor cualquiera. Al parecer -tal como lo definiera Mi-Kyoung Lee-, Protágoras

25 Obsérvese que, tanto aquí como en el pasaje que veremos del Eutidemo, se habla del "círculo" o de los "seguidores" de Protágoras, y no del sofista mismo. Tal vez deberíamos preguntarnos hasta qué punto estas ideas representan al Protágoras histórico, incluso para Platón y para Aristóteles.

${ }^{26}$ AR., Met. 1007b18-30. 
sostuvo un tipo de relativismo infalibilista -es decir que ningún conocimiento es falso, a partir del momento en que ningún individuo puede errar respecto de lo que siente- o un tipo de 'relativismo de hecho' -es decir, que no llegó a elaborar una real teorización de una posición relativista, pero habría concebido que todo es siempre algo en relación a un hombre y a una situación determinadas-. ${ }^{27}$ Sea la que fuere la tesis sostenida por Protágoras, Aristóteles refuta la posibilidad de llegar a un conocimiento verdadero, a partir de las líneas generales de su pensamiento. El filósofo lleva entonces la crítica a sus últimas consecuencias:

"Y es que sería absurdo que a cada cosa le perteneciera su propia negación, pero no le perteneciera la negación de otra cosa que no le pertenece: quiero decir, por ejemplo, que si es verdadero afirmar del hombre que es no-hombre, evidentemente lo será también afirmar que es trirreme o no-trirreme." 28

De manera que las consecuencias de la negación del Principio de noContradicción serían graves, al punto de que hacen posible la asignación de cualquier predicado a cualquier sujeto. Ahora bien, nos interesa retener algunas observaciones que Tomás Calvo ha realizado respecto de la relación que el filósofo establece aquí entre lenguaje y ontología, la base para su crítica a Protágoras. Para hacerlo, Calvo comienza por recordarnos el pasaje del Eutidemo donde Dionisodoro pretende que, quien quiera que Clinias se vuelva sabio -algo que no es actualmente-, desea su muerte, pues desea que sea lo que no es (282c-283e). En el diálogo en que Sócrates y Ctesipo intentan determinar qué significa contradecir, el último señala una diferencia entre 'contradecir' (antilégein) u 'ofender' o 'censurar' (loidoréo), que da lugar a que Dionisodoro declare justamente que es imposible contradecir su opinión: como nadie puede "expresar con palabras lo que no es" (286a3), el discurso falso no expresaría nada y, consecuentemente, no puede contradecir, ya que ni siquiera dice. Finalmente, Ctesipo pregunta:

${ }^{27}$ MI-KYOUNG LEE, 2005, p. 70.

${ }^{28}$ AR., Met. 1007b30-1008a1. 
"En resumen, ¿es imposible -porque a ello va enderezado el argumento, ¿no? - decir lo falso?, pues cuando se habla, ¿se dice verdad o no se dice nada?"29

Y la respuesta de Dionisodoro es afirmativa. El argumento continúa tratando la cuestión de la vacuidad del discurso falso y de la imposibilidad consecuente de equivocarse, tanto al actuar, como al hablar y al pensar. ${ }^{30} \mathrm{El}$ error del "sofisma de la imposibilidad del discurso falso" que aparece en el pasaje residiría -en opinión de Calvo- en dos puntos: a. que no puede 'decirse una cosa', 'decir lo que es' (légonta tà prâgma), pues lo que se 'dice' son las palabras, no las cosas; b. que esas 'cosas' (prágmata) pueden comprenderse en tanto "aquello de lo que se habla" o en tanto "un estado de cosas". 31

Ahora bien, sabemos, a partir de nuestra lectura del fragmento 1 y $6 \mathrm{a}$ de Protágoras, que los prágmata son aquello que resulta de la interacción del hombre y del mundo, pero que para Aristóteles, en cambio, prâgma es el sujeto de una predicación, tanto como el sustrato de las determinaciones de algo. En términos de T. Calvo:
"Esta articulación entre sujeto y determinación, sujeto y predicación, ya está presente en la formulación misma del principio de no-contradicción: es imposible que lo mismo ( $s c$. la misma determinación) sea y no sea en la misma cosa ( $s c$. en el mismo sujeto) al mismo tiempo y en el mismo sentido."32

Evidentemente, entonces, ya desde una perspectiva general del contexto de Metafísica, existe un supuesto ontológico que difiere profundamente del planteo de Protágoras. En la medida en que, para este último, no existen determinaciones antes de que las cosas formen parte de un mundo humano, en la exacta medida en que no existen determinaciones a priori, el lenguaje no se limita a un principio de explicación como el que Aristóteles supone en el pasaje aludido.

\footnotetext{
${ }^{29}$ PL. Eutid. 286a-b.

30 PL. Eutid. 287a.

${ }^{31}$ CALVO, 1988, p. 55-56.

32 CALVO, 1988, p. 55.
} 
Por otro lado, desde el punto de vista particular del planteo de Aristóteles, el Principio de no-Contradicción presenta un problema en sí mismo, a través del concepto de potencialidad. En la medida en que este principio supone una realidad plenamente actualizada, el filósofo habría debido asumir que "no se aplica de la misma manera en todos los dominios de la realidad", ${ }^{33}$ ya que si bien existe la unidad de lo real, la ausencia de movimiento y de potencialidad, esto no corresponde a todos los aspectos de la realidad experimentada por el hombre. El punto de partida del pensamiento aristotélico y del protagórico difieren. Sin embargo, el primero está obligado a aceptar el planteo del sofista, cuando piensa en las condiciones reales de aplicación del principio: una realidad fluctuante y siempre bajo la mirada de una vitalidad particular. En resumen, las antilogías de Protágoras representan la específica relación que el hombre puede tener con la realidad, a través del tamiz del lenguaje.

\section{II}

Veamos ahora lo que sucede con el pensamiento escéptico en lo referente al valor del discurso. La primera dificultad al abordar el tema del escepticismo es la cuestión de las fuentes. La manera indirecta en que se ha conservado el pensamiento de sus representantes más antiguos, Pirrón de Elis y Timón de Fliunte, siempre formará parte de la controversia sobre las interpretaciones de sus pensamientos. La principal fuente con que la tradición cuenta, la obra de Sexto Empírico Esbozos Pirrónicos, adolece de una falta de objetividad debido a la posición del autor, que participa de un escepticismo no necesariamente coincidente, en sus puntos principales, con el de los primeros escépticos.

Lo cierto es que, si hacemos abstracción de los posibles matices de un tipo de escepticismo u otro, hubo toda una serie de conceptos que parecen haber constituido el núcleo escéptico antiguo, representado concretamente por la actitud mostrada -más que teorizada- por Pirrón. Más allá de la inexistencia de una argumentación acerca de la necesidad de suspender el juicio (epoche $)^{34}$ frente a una realidad cuya naturaleza última es imposible de

${ }^{33}$ CALVO, 1988, p. 69. Ar., Mét. 1009a34-36.

34 BURNYEAT, 1976, p. 44-45. 
conocer -argumentación que, por otro lado, al confiar en la eficacia del discurso, daría por tierra con el argumento mismo-, la actitud del filósofo se caracterizó por la preocupación por llegar a un estado mental de imperturbabilidad que suele llamarse 'indiferencia' (adiaphoría), de una actitud de impasividad (apátheia) y de una tranquilidad (atáraxia); indudablemente, ellos traducen una concepción sobre la posibilidad de acceder a lo real y sobre las limitaciones de nuestros estados perceptivos.

Timón ${ }^{35}$ constituye tal vez la fuente más antigua sobre el pensamiento de Pirrón, y en consecuencia sería una de las mejores. Es en su testimonio donde encontramos la declaración de que Pirrón ha sido el autor de este punto de vista filosófico y las consecuencias principales que en ella ha visto, desde el punto de vista epistemológico. Es difícil determinar hasta qué punto la interpretación de Timón sigue de cerca el pensamiento que comenta, dado que probablemente "Pirrón haya sido un sabio moral no-sistemático". ${ }^{36}$ Pero poniendo su testimonio en la perspectiva de la evidencia provista por Diógenes Laercio ${ }^{37}$-quien, por otro lado, da cuenta del pensamiento del propio Timón a continuación del de Pirrón-, podemos concluir que la actitud de la indiferencia ha sido la más característica del escéptico y el ideal del estado de conciencia que proponía. La reclusión, el contacto limitado y un tanto mezquino con sus amigos, tanto como el contacto y los intercambios con extraños ${ }^{38}$ ha sido lo que el pirronismo posterior tomó del pensador. La indiferencia mostrada frente a su amigo Anaxarco caído a un pozo parece evidenciar un estado de conciencia privilegiado por Pirrón; ${ }^{39}$ lo mismo vale para la anécdota que lo muestra hablando sin ningún interés en que alguien esté escuchándolo. ${ }^{40} \mathrm{Tal}$ como Bett concluye,

"La conducta caracterizada por este estado de conciencia [impasividad, apátheia], mientras que ni fue suicida ni requirió la constante vigilancia de sus compañeros, es

${ }^{35}$ DIELS 21.

${ }^{36}$ BETT, 2010, p. 37.

${ }^{37}$ D.L. IX 62-108.

38 D.L. IX 66, 63.

${ }^{39}$ D.L. IX 66 .

${ }^{40}$ D.L. IX 64. 
ciertamente no convencional, incluso haciendo ostentación de aceptación social." 41

A partir de la filosofía y de la razón -informan Plutarco y Diógenes Laercio-42 Pirrón pensaba que es posible que las opiniones y las afecciones no perturben los estados mentales. En la base de esta concepción aparece la idea de que, en verdad, no está en nuestra naturaleza el conocer nada. A este respecto, resulta importante revisar el pasaje en que Aristocles transmite el testimonio de Timón; allí nos informamos de que para Pirrón habría que reflexionar sobre estas tres preguntas para acercarnos al estado de felicidad: 1. ¿cómo son las cosas por naturaleza? 2. ¿qué disposición deberíamos tener hacia ellas? 3. ¿qué les sucedería a quienes están dispuestos de ese modo?43 Inmediatamente después de detallar estos cuestionamientos, Aristocles puntualiza que Pirrón declaró:

"las cosas son igualmente indiferenciables, inconmensurables e indecidibles (adiaphorá kai astathméta kai anepíkrita); debido a esto, ni nuestras percepciones ni nuestras opiniones dicen verdad o falsedad (dià toûto mête tàs aisthéseis mête dóxas alethéuein è pseúdesthai)." ${ }^{\prime 4}$

La consecuencia de esta posición -termina diciendo Aristocles- es la suspensión del juicio y la tranquilidad (ataráxia). La cuestión principal parece haber sido entonces cómo lograr un estado de felicidad. Tenemos allí un punto nodal del pensamiento pirroniano, que lo ha llevado a preocuparse por la manera en que la realidad afecta al hombre. La manera en que nuestra sensibilidad se pone en movimiento fue un problema derivado de la cuestión moral. Si la búsqueda del hombre sabio es la de la impasividad, debe estar en condiciones, en primer lugar, de evaluar cómo nos volvemos menos impasibles frente a lo que nos sucede y, en segundo lugar, cómo lograr -en la medida en que es humanamente posible- el dominio de sí en las circunstancias que enfrentamos. Es precisamente en el primero de estos puntos donde encontramos rasgos del pensamiento de Protágoras, pues es allí donde el

\footnotetext{
41 BETT, 2010, p. 40.

42 PLUT., Sobre Progreso Moral, 82f. y D.L. IX 66.

${ }^{43}$ ARISTOCLES, en Eusebio Praep. Evang. XIV, 18 1-ss. (versión en R. Bett, Op. cit.; p. 41).

${ }^{44}$ ARISTOCLES, en Eusebio Praep. Evang. XIV, 18 2-ss.
} 
escepticismo considera la constitución de la realidad y la epistemología que es posible desprender de ella en conjunción con el hombre.

La afirmación de que nuestras percepciones y opiniones no nos dicen ni la verdad ni cosas falsas evoca directamente las formulaciones del fragmento 6 de Protágoras. La manera de presentar el problema no es ciertamente el mismo. Sin embargo, el juicio sobre la realidad pone un límite en la competencia humana de penetrar en lo que es casi en la misma extensión que el presentado por el Abderita. El testimonio de Aristóteles nos dice que las cosas son indiferentes, inconmensurables, indecidibles, ${ }^{45}$ prácticamente las mismas características que el mundo fluctuante y constantemente renovado del relativista. El escepticismo profundiza un poco aquel planteo, y no considera la posibilidad de que las definiciones o diferenciaciones de las cosas puedan apreciarse en la particularidad deviniente de cada momento. El escepticismo no se detiene en esta parcialización; considera el profundo límite humano en la determinación o decisión de cómo es la realidad. Tal como observa R. Bett, esta perspectiva adscribe a Pirrón una observación de

"nuestro defecto cognitivo, y uno podría argumentar que los adjetivos de 1a [=Eus. Praep. Evang. 14, 18 3: "las cosas son igualmente indiferenciables, inconmensurables e indecidibles"] se comprenden mejor de este modo, especialmente el adjetivo anepíkritos, "indecidible". Llamemos a esta lectura de adjetivos subjetivos, ella trae al foro el tema común a Pirrón y Sexto: una falta de habilidad para decidir cómo son las cosas." 46

Esta interpretación, incluso apelando al anacrónico concepto de sujeto, refleja lo que el Abderita concibió como el límite del hombre para acceder a lo real, por ser él mismo de naturaleza deviniente. La perspectiva que hemos llamado diacrónica, que remite al tránsito de la vida del hombre que lo coloca constantemente en una nueva situación, causa de la necesidad de la constante resignificación de la vida y de los valores humanos, se traduciría de esta manera en el pensamiento de Pirrón. Sería la cuestión de la intersubjetividad -que también señalamos como una de las variables que

45 BETT, 2010, p. 42.

46 Idem. 
hacen posible al hombre la construcción de un mundo social-, la que matiza en cierta forma lo indecidible e indiferenciable del mundo escéptico.

Pero, tal como R. Bett explica, paralelamente a esta lectura subjetiva, la crítica ha desarrollado una interpretación objetiva de la posición de Pirrón, que haría posible traducir el testimonio de Eusebio citado como "las cosas son igualmente indiferentes, inestables e indeterminadas". ${ }^{47} \mathrm{La}$ principal objeción de que sería pasible esta lectura es la falta de coherencia que implicaría, por parte de un escéptico, hacer juicios sobre la realidad; al menos desde el punto de vista de intérpretes como Sexto Empírico, Pirrón se volvería así un pensador dogmático. Difícilmente sea ésta la manera en que el escéptico ha concebido el problema del límite humano, pero incluso si este fuera el caso, encontramos aquí ecos de Protágoras, asumiendo -tal como interpretamos a partir de 80B1- que la realidad misma del viento es fría y caliente, que lo que es posee todas las determinaciones, y que es cada hombre, en circunstancias determinadas, quien selecciona algunas y es incapaz de percibir otras. Vale decir que el juicio sobre una realidad indeterminada nos permitiría encontrar nuevos puentes entre el relativismo y el primer escepticismo. En rigor, si consideramos que esta línea de lectura no es digna de profundizarse, es porque los testimonios insisten en comprender anepíkrita como 'indecidible'. El adjetivo anepíkritos tiene ciertamente ambos acepciones ('indeterminado', 'indistinto' e 'indefinido'), pero si vemos que en los usos médicos también significa 'no evaluado' ('untested'), 'no probado' ('untried'), ${ }^{48} \mathrm{y}$ que tardíamente adquiere principalmente el valor semántico de 'no examinado'49 se suman razones para seguir las lecturas subjetivas.

Siguiendo con el mismo pasaje de Aristocles, leemos la explicación que Timón habría dado:

"Por esta razón, entonces, no debemos confiar en ellas, sino que debemos permanecer sin opiniones (adoxastoús), no inclinarnos hacia ningún lado (aklineís) y permanecer inquebrantables (akrádantous), diciendo que a cada cosa individual no le concierne más ser que no ser, o ser y no ser,

\footnotetext{
47 BETT, 2010, p. 42-43. Para un análisis detallado de las lecturas subjetivas y objetivos, cf. pp. 42-47. No seguimos aquí, sin embargo, la posición del autor, quien se inclina por esta última interpretación.

${ }^{48}$ Cf. por ejemplo GALEN. I.78.

${ }^{49}$ SIMPL. In Phys. 1148.29.
} 
o ni ser ni no ser (ou mâllon éstin è ouk éstin è kai éstin kai ouk éstin è oúte éstin oúte ouk éstin)." 50

La idea del parágrafo anterior se precisa: como nuestra capacidad para decidir cómo es la realidad es limitada, debemos permanecer sin opinión, no dejarnos llevar hacia la evaluación de un hecho como verdadero o como falso. De hecho, inmediatamente después Timón explica la razón ontológica por la cual nuestra opinión, cualquiera que ésta fuere, traiciona la realidad: si a nada conviene el ser más que el no ser, o si a todo conviene el ser y el no ser, ¿cómo poder emitir un juicio verdadero o falso? La última sentencia de la cita -que conserva todavía ecos del pensamiento parmenídeo y gorgiano, más allá del aire de familia con la posición relativista sobre la que reflexionamosparece dar la clave para comprender la posición epistemológica pirroniana: la imposibilidad de un juicio verdadero o de un juicio falso, de la adscripción de una calidad veritativa determinada a una opinión, reside en la imposibilidad de decir si cada cosa es o no es, o es y no es. Tal como queda expresado, es al menos cierto que existe una profunda limitación humana para determinar estas maneras o grados de existencia, que imposibilita, a su vez, la posibilidad de definir si la realidad es en sí misma definida. Vale decir que la posición pirroniana, al menos en lo que al testimonio de Timón se refiere, al observar el defecto de la capacidad humana de conocer, se vio obligada a asumir la indeterminabilidad, desde el punto de vista del hombre, de la naturaleza de la realidad. Es precisamente la limitación humana la que abre una brecha de indecidibilidad de lo real, y es imposible ni siquiera declarar la naturaleza de las cosas. Pirrón se quedaría dentro de los límites de lo humano; la abstención del juicio deja claro que ni siquiera vale la pena intentar ocuparse de la naturaleza de lo real. La última parte de nuestra cita, la expresión ou mâllon éstin, emblemática de Pirrón, se comprende mejor a la luz de la explicación de Sexto Empírico:

"Y aunque ciertamente la expresión "nada es más" (ou mâllon éstin) podría denotar un matiz de asentimiento o negación, nosotros no la usamos así, sino que la tomamos en un sentido vago e impropio, bien en lugar de una forma interrogativa, bien en lugar de decir "no sé a cuál de estas dos

${ }^{50}$ ARISTOCLES, en Eusebio Praep. Evang. XIV, 18 3-ss. 
asentir y a cuál no asentir". Para nosotros cuenta lo de dejar claro lo que se impone a nuestra percepción." 51

Es la limitación de la percepción, dada por la fluctuación y cambios que muestran su inestabilidad, lo que llevó a Pirrón a la ausencia de predicación. En la medida en que el lenguaje es una herramienta para hablar de esa realidad escurridiza, toda predicación es aproximativa, "vaga e impropia”; y esto incluye el principio de la predicación, ou mâllon éstin. La coherencia de la posición no descuida ninguno de los puntos que la harían auto-invaldarse. Es por esto que al parágrafo final del pasaje de los Esbozos citado, Sexto insiste en que el uso de esta expresión se hace "sin estar seguros de que ella sea absolutamente verdadera e indudable". ${ }^{52}$ En este mismo marco, la explicitación de las consecuencias de esta posición respecto de la ontología en el ámbito discursivo no se hacen esperar. Sexto puntualiza inmediatamente sobre he aphasía, sobre 'no afirmar nada', que debe entenderse como la negación en sentido restringido: denotando tanto la afirmación como la negación, "según la cual decimos que ni se establece ni se rechaza nada". ${ }^{33} \mathrm{Y}$ agrega:

\footnotetext{
"También debe tenerse presente esto: que decimos que no se establece ni se rechaza nada acerca de las cosas que sobre algo no manifiesto se dicen dogmáticamente; porque a las cosas que nos afectan sensitivamente $\mathrm{y}$ nos inducen al asentimiento independientemente de nuestra voluntad, a ésas sí asentimos. ${ }^{" 54}$
}

Como se ve, el final del pasaje recupera en su esencia las antilogías de Protágoras: en el espacio que queda dentro de nuestra percepción y nuestra sensibilidad, en lo que nos afecta subjetivamente, allí no hay lugar para la duda o para la abstención del juicio. En este sentido, toda percepción es infalible. El problema aparece respecto de aquello que no nos pertenece, que no es nosotros mismo ni nuestro sentir: la realidad; y he ahí donde el juicio encuentra su límite. Creemos encontrar prueba de la corrección de esta interpretación en el pasaje I, 191 de Adversus Matemáticos que, aunque sin

\footnotetext{
51 SEXTO EMP., Esb. Pirr. I 191.

52 SEXTO EMP., Esb. Pirr. I 191.

53 SEXTO EMP., Esb. Pirr. I 192.

54 SEXTO EMP., Esb. Pirr. I 193.
} 
referirlo directamente a Pirrón, presenta la idea de que la predicación verdadera y falsa se sustenta siempre en la validez de todo lo que se dice. Como en el caso del sentido 'genérico' de 'no afirmar nada', que incluye tanto afirmación como negación, siempre hay un sustrato de predicación que haría válido todo discurso.

\section{III}

Digamos, para concluir brevemente, que desde Heráclito hasta Pirrón encontramos una denuncia del límite a la decisión de cómo es la realidad, originado en la contradicción e inestabilidad propias de las percepciones. Las apariencias perceptivas señalan la limitación humana frente a la certeza de que la realidad es $F$ o no- $F$, y es precisamente sobre este punto que la respuesta de Protágoras y de Pirrón se acercan. Tres son los puntos en los que el planteo epistemológico de ambos se encuentran: ambos adhieren a la idea de que los desacuerdos entre las declaraciones de diferentes hombres son generales e irresolubles: "en los dos puntos de vista, está supuesto que las cosas aparecen como $F$ para algunos y como no- $F$ para otros". ${ }^{55}$ Ambos niegan la posibilidad de establecer una correspondencia entre nuestras percepciones y la realidad; el establecimiento de un criterio de verdad como correspondencia es por ende imposible; plantearse una investigación sobre las características de ontológicas de aquello que corresponde a nuestra percepción es, para ambas posiciones, una tarea sin sentido. ${ }^{56}$ Ambas posiciones afirman, como consecuencia de lo que acabamos de establecer, que toda percepción depende del perceptor, que las cosas pueden concebirse sólo a partir de la manera en que alguien las siente, y que en consecuencia no hay posibilidad de superar el conflicto entre lo que diferentes hombres sienten.

Ahora bien, hay sin embargo y más allá de estas coincidencias en los planteos básicos de ambos, una pequeña diferencia de perspectiva en la manera de solucionar la imposibilidad de decidir sobre la realidad. Mientras que para el sofista la realidad se define en el encuentro del hombre con una exterioridad, es decir que hay determinación y se concibe la realidad como

\footnotetext{
55 BETT, 2010, p. 27.

${ }^{56}$ Contrariamente a nuestra conclusion, R. Bett ve una diferencia de perspectiva entre ambos filósofos en este punto y el siguiente (2010, p. 27).
} 
decidida, en el caso de Pirrón el límite queda establecido completamente en el espacio interior del hombre; no hay, por tanto, posibilidad de esbozar ninguna característica de la realidad misma.

Sin embargo, no hay diferencias reales entre ambos pensadores, en la valoración que hacen de la predicación: tanto Protágoras como Pirrón muestran una total aceptación de cualquier predicación como verdadera, ya que en los dos planteos siempre, sea en la afirmación o en la negación de una predicación -tal como Platón señaló en Eutidemo-, existe una predicación. Y en la medida en que tal predicación se enraíza en la percepción particular de un hombre, simplemente es. Lo que Protágoras concibe como la imposibilidad de contradecir, es expresado en los testimonios de Pirrón como la aceptación total de toda afirmación. No hay diferencia entre ellos en este punto, pues hay claramente una imposibilidad de determinar una 'versión' de la realidad, un discurso con un valor verdadero, en contraposición con otro que no lo es. La convicción del sofista de poder establecer grados de una realidad mejor y peor inserta su planteo en una realidad respecto de la cual Pirrón se mostró un tanto más cauto y lejano. 


\section{Referências Bibliográficas}

AAVV, Los Sofistas. Testimonios y Fragmentos (Trad. A. Melero Bellido). Madrid: Gredos, 1996.

ARISTÓTELES, Metafísica (Intr., trad. y notas Tomás Calvo). Madrid: Gredos, 1994 (reimpr. 2000)

ALERCE, D. Vie et Doctrine des Philosophes Illuestres (Trad. fr. M.-O. Goulet Cazé). Paris: Livre de Poche (La Pochotèque), 1999.

PLATÓN. Diálogos II: Eutidemo (Trad. esp. Francisco Olivieri) Madrid: Gredos, 1990

SEXTO EMPÍRICO. Esbozos Pirrónicos (Trad. A. Gallego Cao y T. Muñoz Diego). Madrid: Planeta, 1999.

BURNYEAT, M. "Protagoras and Self-refutaton in later Greek philosophy". The Philosophical Review, LXXXV, 1 (1976), p. 44-69.

BETT, R. Ancient Scepticism. Cambridge: Univesrity Press, 2010.

CALVO, T. "El principio de no contradicción en Aristóteles: Sus presupuestos e implicaciones de carácter ontológico”. Méthexis I, 1988, p. 5370.

LEE, M.-K. Epistemology After Protagoras. Oxford: Clarendon Press, 2005. KERFERD, G. The Sophists and Their Legacy, Steiner Verlag, Wiesbaden (ed. especial de Hermes. Zeitschrift für Klassische Philologie, Heft 4) 1981.

SCHIAPPA, E. Protagoras and Logos. A Study in Greek Philosophy and Rhetoric. South Carolina: University of South Carolina Press, 2003.

UNTERSTEINER, M. Les Sophistes (Trad. franc. Alonso Tordesillas). Paris: Vrin, 1993. 